\title{
EL LÉXICO REFERIDO A JOVEN Y JUVENTUD EN LA LENGUA ESPAÑOLA ${ }^{1}$
}

\author{
*JUAN PABLO REYES NÚÑEZ
}

\begin{abstract}
RESUMEN
El presente artículo propone un método de análisis interdisciplinario aplicado a los apodos sociopolíticos de la lengua española, referidos a joven y juventud, a través de un estudio histórico y semántico, para establecer características del imaginario social respecto del sujeto joven.
\end{abstract}

PALABRAS CLAVE: APODOS, JÓVENES, COMUNICACIÓN SOCIAL

\section{O LÉXICO REFERIDO A JOVEM E JUVENTUDE NA LÍNGUA ESPANHOLA}

\section{RESUMO}

Este artigo propõe um método de análise interdisciplinar aplicado aos apelidos sociopolíticos da língua espanhola, referindo-se a jovem e juventude, através de um estudo histórico e semântico, para estabelecer características do imaginário social em relação ao sujeito jovem.

PALAVRAS-CHAVE: APELIDOS, JOVENS, COMUNICAÇÃO SOCIAL

* Juan Pablo Reyes Núñez, profesor de Estado en Castellano, magíster en Lingüística, doctor en Lingüística Románica, director del Centro de Estudios Dialectológicos de la Universidad de Playa Ancha, Valparaíso, Chile. Investigación DGI regular 2009 HUMI 02-10, DGI regular 02-1617. Correo electrónico: jreyes@upla.cl 


\title{
THE LEXICON REFERRED TO YOUNG PEOPLE AND YOUTH IN SPANISH LANGUAGE
}

\begin{abstract}
In order to establish the features of the social imaginary regarding young individual, the present article proposes a method of interdisciplinary analysis of sociopolitical nicknames of the Spanish language related to young people and youth, through a historical and semantic analysis.
\end{abstract}

KEYWORDS: NICKNAMES, YOUNG PEOPLE, SOCIAL COMMUNICATION. 


\section{INTRODUCCIÓN}

En este artículo pretendo dar cuenta de una parte del repertorio léxico de la lengua española, referido a la juventud y al joven, con el propósito de analizar sus contenidos semánticos y establecer las representaciones sociales que, de este segmento, tiene la sociedad, específicamente, la sociedad dominada por adultos (Duarte, 2012).

Para esto, he escogido un recurso expresivo, el apodo, que forma parte de la tradición idiomática más emblemática, puesto que entrega una serie de connotaciones y metáforas, usadas para designar aspectos «juveniles» de la vida y dan cuenta del joven como actor o sujeto histórico. Por lo tanto, solo nos concentramos en aspectos que digan relación con las características sociopolíticas de personas o seres humanos jóvenes; de esos actores nombrados, pero no necesariamente investigados en los relatos historiográficos: «Los niños y los jóvenes no figuran, normalmente, en las páginas de la Historia» (Salazar, 2002: 9).

En definitiva, estamos en la conceptualización de las palabras que incluyan referencias a juventud y joven, y que sean parte de la producción simbólica de la sociedad, en este caso, de la sociedad occidental hispana y latinoamericana.

Buscamos, por cierto, el imaginario que hay respecto de juventud y joven, esto es, los valores sociales que constituyen los rasgos distintivos del apodo sociopolítico y que forman parte de las redes simbólicas que arman una figura de la realidad. Este símbolo verbal informa de asociaciones de rasgos, condiciones, características raciales, psicológicas, físicas, vestimenta, alimentación, etc., que la sociedad valora positiva o negativamente en conceptos dicotómicos:

Los actos de diferenciación, si bien pueden tener sus raíces en la concepción binaria de la realidad, en tanto que hablamos de alto y bajo, bueno y malo, se diferencia de ella, en la medida que cada uno de sus elementos representa un valor $\mathrm{y}$, en tanto que, los elementos diferenciadores son definidos socioculturalmente y también responden a variables históricas. (Magendzo y Donoso, 2000: 81)

Las expresiones escogidas son construcciones sociales, mejor aún, construcciones sociolingüísticas, como la edad, la actividad, el cuerpo, y se determina la aceptación o rechazo social de la persona, de los acontecimientos, de las palabras, e incluso, hasta de la noche, del día, de los colores, del sabor, del olor, de las estaturas del cuerpo, de los peinados, etc. Con ello, va creándose una red de significaciones que estructuran una imagen del mundo y los seres sociales e individuales 


\section{DEFINICIÓN DEL APODO SOCIOPOLÍTICO QUE DESIGNA A JOVEN Y JUVENTUD}

El apodo es una forma idiomática que da cuenta de la inserción sociopolítica del individuo. Esta inserción se hace de acuerdo a ciertos parámetros que la comunidad, el grupo o la sociedad que lo reciben, imponen según apreciaciones que lo incorporan, pero no necesariamente lo integran. Porque el apodo solo da cuenta de un aspecto superficial de la persona, vestimenta, cuerpo y trabajo.

En este sentido, los apodos a las personas dicen otro tipo de contenido que los nombres de pila. Son la marca o el distintivo que dan cuenta de la forma en que lo perciben, lo tratan y lo valoran, social e históricamente, a nivel de un uso informal, familiar, coloquial, de la lengua, en cambio, el nombre de pila se usa en contextos comunicativos formales, cultos, alfabéticos.

El sobrenombre —el cognomen - es una aposición del sujeto de una proposición que evoca una empresa memorable; esto es lo que vincula al individuo con la historia y lo expone, por así decirlo, al panteón de la memoria colectiva. (Campa, 1998: 37)

El apodo, en este caso, se define como un recurso expresivo, que se impone sobre el nombre de pila y, para el caso particular de este estudio, se usa para referirse de manera estereotipada a grupos o comunidades de personas, con el propósito de dominar. Por eso, el apodo es una síntesis de información abundante y variada respecto de formas de tratarse, intenciones comunicativas, tamaños, formas, distancias, circunstancias, aspectos psicosociales, asociadas a personas, animales, cosas y circunstancias.

A veces, estas líneas de negatividad o positividad se ven alteradas por otros hechos y, se dice, por ejemplo, «blanco pobre», cuando es un rico empobrecido, en una época en que no había negros ricos, en consecuencia, no tenía sentido decir negro pobre o incluso negro esclavo. Hoy, afortunadamente, eso cambió.

Sin embargo, predomina un trato social en el apodo según clase, estatus o condición económica, social y política. Por ejemplo, si se trata de hechos delictuales, encontramos diferentes denominaciones para «ladrón», según pertenezca, a la parte de «abajo» o a la parte de «arriba» de la escala social, así, uno será llamado «cuma», «flaite», «chusma», «ratero» y, el otro será nombrado «estafador de alta escuela», «ladrón de cuello y corbata», «ladrón de tarro y levita», «agiotista», «estanquero» o «negligente», respectivamente:

El desprecio se inspira y alimenta de una ficción identitaria, de la invención de una esencia asociada a la clase, de la elaboración de una verdad de tipo 
sociológica que asigna un tipo de comportamiento a un grupo social específico, negándoselo a otro. (Gaune y Lara, 2009: 320)

Debemos entender, entonces, que, entre las formas de tratar al otro, mediante recursos nominativos, están:

los apodos de grupo y de raza, creados más o menos irrespetuosamente con un sentido humorístico peyorativo, como resultado de la natural rivalidad entre las clases sociales en competencia y entre los vecinos y regiones vecinas dentro de un país. (Kany, 1962: 33)

También agreguemos, entre etnias, grupos etarios, género, distribución geográfica urbano-rural, actividades, oficios, profesiones, deportes, clubes, establecimientos educacionales, etc.

Así entendido, el apodo, en gran parte, está motivado y dirigido desde las valoraciones sociales que se tengan de la juventud, según pertenezca a la clase alta o a la clase baja. Los siguientes ejemplos dan cuenta de esa diferencia, que el imaginario social tiene, respecto de los jóvenes: «señorito», «niño rico», «hijito de papá», «niño bien» o, al contrario, «warrior», «camboyana», «cabro», «jovenzuelo», «mozo».

El lenguaje se encarga de representar estas tensiones históricas entre los segmentos señalados. Los vocablos registran $\mathrm{y}$, de algún modo, archivan información de la sociedad en la que se desarrollan y ayudan a desarrollar, por eso es que:

se trata (...) de recuperar un conjunto de experiencias históricas a través de las huellas que deja en el lenguaje y, a la vez, observar simultáneamente cómo la categoría usada para categorizar los hechos presupone ciertas pautas de comprensión del mundo dentro de los cuales se desenvuelven los grupos sociales. (Torres, 2010: 25)

Esto es el nominar para dominar, afirmación que desarrollaré en torno a nominaciones de adultos dominantes o de la elite adinerada (Torres, 2010) referidas a jóvenes dominados y pobres, y considerando la visión que tenían los primeros respecto de los segundos:

La subvaloración de los sectores populares, los que eran vistos como infrahumanos. (...) Las descripciones que se hacen de ellos correspondían a seres con una racionalidad inferior. Ese era básico en la imagen que las clases dirigentes de la época tenían del pueblo, por lo menos lo era entre los grupos 
que se negaban a definir al pueblo de una manera idílica y pastoril. (Torres, 2010: 80)

Esta afirmación no solo es válida para los siglos XIX y XX, sino también para los tiempos de ña Colonia. Esto lo corrobora Kany (1962) respecto de las asociaciones con la palabra indio, que tiene aún un significado negativo, unido con los conceptos de: «Clase inferior, sirviente, inculto, tosco, de piel oscura, con un matiz peyorativo o humorístico» (Kany, 1962: 32).

Las acepciones de los vocablos, que significan joven y juventud, son las que nos permitirán, a su vez, establecer asociaciones de sentido entre el nombre de algún referente y alguna condición, característica o cualidad de otro referente.

\section{MÉTOdo}

Considerando que el lenguaje juega un papel de fundamental importancia en la transmisión, comunicación y permanente reconstrucción de símbolos y significados, y que el imaginario se mueve en una esfera social, en la que se materializan y comparten los productos de la imaginación, a través de la comunicación que se da entre las personas, es que, metodológicamente, se infiere que al analizar semánticamente los apodos sociopolíticos, es posible obtener los imaginarios sociales presentes en las comparaciones estereotipadas usadas por los informantes.

\section{ANÁLISIS}

El lenguaje ya no solo expresa la realidad, sino que la constituye y la construye, la produce y reproduce, utilizando un tejido textual, simbólico y conceptual. Esta red es tejida de acuerdo a un modelo «adultocentrista» de la sociedad, esto es, desde una ideología o imaginario adulto superior.

He tomado una palabra que designe algún rasgo respecto de joven o juventud, para establecer las conexiones semánticas con otros nombres que nombren el mismo rasgo, y luego, encontrar elementos comunes y categorizarlos, de modo que, al unirlos, determinemos una representación lo más amplia posible del sujeto joven y de la idea de juventud.

Propongo proceder de la siguiente manera: elijo del Diccionario de la Real Academia Española de la lengua (DRAE, 2001) la palabra pincho, cha: «(De pinchar). 1. adj. coloq. Compuesto, bien vestido. 2. m. Aguijón o punta aguda de hierro u otra materia. 3. m. Varilla de acero, como de un metro de longitud, con mango en un extremo y punta a veces dentada en el otro, con que los 
consumeros y aduaneros reconocen las cargas. 4. m. Porción de comida tomada como aperitivo, que a veces se atraviesa con un palillo. 5. m. Guapo mozo, presumido, matón, jactancioso. 6. m. vulg. Perú. pene. 7. f. Espina de plantas o pescados que puede clavarse en el cuerpo. 8. f. Mujer que presta servicios auxiliares en la cocina».

El primer paso es encontrar alguna referencia a joven, que es hacia donde queremos llegar como concepto fundamental. Pues bien, la encontramos en la acepción 5, en la que se alude a «mozo», «guapo», «presumido», «matón», «jactancioso». En tanto en la acepción 1, encontramos otra alusión a una persona, pero no por su edad, sino por su apariencia al vestir. En la acepción 8 hay una relación semántica entre persona y el nombre pincho, desde el punto de vista del género y laboral. El resto alude a la cualidad literal de pinchar, clavar, picar.

$\mathrm{Al}$ respecto, encontramos la palabra pícaro, que en su acepción de pícaro de la cocina aparece pinche, término al que se le dan las siguientes acepciones: «Pinche. 1. com. Persona que presta servicios auxiliares en la cocina. 2. adj. $C$. Rica, El Salv. y Nic. tacaño (\| miserable). 3. adj. despect. malson. Méx. ruin (\| despreciable)».

Aunque, parcialmente, podemos sostener que la relación entre joven y pinchar estaría en realizar una labor auxiliar de pinchar. Es decir, un apodo en que se recurre a la sinécdoque, como es en la mayoría de los casos que se entregan en este artículo. Es decir, se restringe el nombre joven a una actividad. Por lo tanto, pincho, pincha y pinche vendrían a asociarse a joven que realiza labores auxiliares en la cocina, pero también tiene ciertas formas de vestir y de comportarse socialmente.

Ahora, pasemos a la acepción 5, para especificar la relación entre pincho y las características que en ella se indican: «Mozo-a1. adj. joven (\| de poca edad). 2. adj. Célibe, soltero. U. t. c. s. 3. adj. mocero. 4. m. y f. joven (\| persona que está en la juventud). $5 . \mathrm{m}$. Hombre que sirve en las casas o al público en oficios humildes. Mozo de café, de comedor, de cocina. 6. m. Individuo sometido a servicio militar, desde que es alistado hasta que ingresa en la caja de reclutamiento. $7 . \mathrm{m}$. cuelgacapas. $8 . \mathrm{m}$. tentemozo (\| puntal de una cosa expuesta a caerse). 9. m. Ingen. Sostén sobre el que gira la palanca de un fuelle. 10. m. germ. garabato (\| instrumento metálico que sirve para colgar o asir). 11. f. Criada que sirve en menesteres humildes y de tráfago. 12. f. Pala con que las lavanderas golpean la ropa, especialmente la gruesa, para poder lavarla más fácilmente. 13. f. Pieza de las trébedes, en forma de horquilla, en que se asegura el rabo de la sartén. 14. f. En algunos juegos, última mano. 15. f. p. us. Mujer que mantiene trato ilícito con alguno».

En las acepciones de la palabra mozo se encuentran distintos ámbitos sociales. Herramientas y las partes de herramientas, así como aspectos morales, etapa del juego de naipes y estado civil, son conceptos asociados a la palabra en 
cuestión. Es necesario decir, que no todas las acepciones son conocidas por todos los hablantes y que la más familiar es la de «sirviente»o «criado». Además, las siete primeras acepciones se refieren, de manera más o menos explícita, a joven. Se repite lo de la actividad o trabajo, en este caso, oficio, menester humilde, pero no por eso menos complicados, cansadores e incómodos («y de tráfago»).

En el DRAE aparecen la relación del mozo con tipos de criados, as y sirvientes, as que se ocupan en las haciendas y en la policía: moza de cámara, de cántaro, moza o moza del partido, mozo de caballos, de cordel, de cuadra, de escuadra, de espuela, de esquina, de estoques, de mulas, de oficio, de paja y cebada.

El segundo paso consiste en reunir los elementos comunes de las acepciones del tipo buscado. Ahora podemos indicar, a juzgar por el tipo de actividad nombrada, que se trata de jóvenes campesinos de condición sociocultural baja. La cantidad de servicios en los que se emplean estos jóvenes indica que eran muy requeridos y que había bastantes quehaceres, de cuya responsabilidad estaban a cargo jóvenes, pero esas responsabilidades son consideradas auxiliares, menores o de segundo orden, poco trascendentales.

Hay aspectos sexistas también incluidos dentro de mozo, moza, en la acepción 3, con la palabra mocero, que alude a la lascivia y al trato de las mujeres. Este tipo de alusiones será recuperado en otros términos referentes a joven y juventud, frecuentemente atribuidos más a la mujer que al hombre.

En cuanto a la frase buen na moza, esta establece la relación entre mozo, a y la apariencia, generalmente, referida a la belleza de su cuerpo y de su forma de vestirlo. Distinto sería hablar de buen lolo o buen joven, que aluden a la cualidad de tipo ética. Por lo que habría que indagar más en el origen de esta expresión que, por ocupar la expresión «moza», debería ser de origen rural y haber sido utilizada en las haciendas. Sin embargo, podría haber pasado al uso urbano sin el sentido de actividad, sino solo de edad y cuerpo.

Al respecto, Rodríguez (1875, facsímil 1977) hace un interesante comentario filológico:

Puede ser que chino i sus derivados traigan su orijen del quichua, pues en esta lengua se llama china a la criada o moza de servicio (...) en la América republicana somos demasiado demócratas para hablar de plebeyos, somos lo bastante caballeros para no tener un vocablo que nos permita designar a las personas de baja alcurnia sin acudir a sutiles distinciones de indios, mestizos, zambos i mulatos. (Rodríguez, 1877: 163)

El DRAE incluye la palabra chino con la acepción latinoamericana recién en la edición del año 1899 y la mantiene con modificaciones hasta su última 
versión. Entre los vocablos incorporados como acepción están chino cholo (Perú), lampiño y desnudo (Venezuela), niño (Colombia), criado o sirviente de rasgos aindiados (Argentina), niñera (en Centroamérica), mujer (Argentina), servidor (Colombia, Chile).

Queda, con esto, establecida la relación entre clase social y raza, ya mencionada en este artículo, y, por otro lado, la cita nos informa de las preferencias léxicas del siglo XIX y las anteriores centurias, para designar a los jóvenes (pobres) trabajadores de hacienda.

Sigamos con el vocablo joven, otra de las acepciones de la palabra mozo, que está en el DRAE, como sigue: «Joven. (Del lat. iuvěnis). 1. adj. De poca edad. 2. adj. Dicho de un animal: Que aún no ha llegado a la madurez sexual, o, si se desarrolla con metamorfosis, que ha alcanzado la última fase de esta y el aspecto de los adultos. 3. com. Persona que está en la juventud. $\sim$ de lenguas. 1. $\mathrm{m}$. En algunos Estados europeos, funcionario de la categoría de entrada en la carrera de intérpretes para el extranjero al servicio de las misiones diplomáticas establecidas en países orientales. $\square \mathrm{V}$. dama joven 1. f. Actriz que desempeña los papeles de mujer muy joven».

Se empieza, paulatinamente, a notar que las distintas acepciones de los vocablos seleccionados convergen en conceptos próximos o afines. Esta sustancia semántica común se expresa en definiciones como: «muy joven», «poca edad», «entrada de la carrera», «que aún no ha llegado a la madurez», «que está en la juventud». Las anteriores frases dan cabida a imaginar la palabra joven y ver en ella al joven, como un ser que ha vivido poco o, a lo menos, tiene poca experiencia en la vida, que trabaja en actividades auxiliares, etc.

Como tercer paso, es conveniente, para seguir ahondado en lo que podríamos denominar la «trayectoria» de la palabra joven, indicar con qué otras palabras se une para formar una estructura sintáctica con sentido. Los casos que nombro nos permiten comprobar nuevos vínculos semánticos, en los que surgen aspectos ideológicos sustanciales a la palabra joven, por ejemplo, patria joven, poder joven, juventud dorada, joven Luis, jovencito, jovenzuelo, juventudes comunistas, juventud rebelde Miguel Henríquez, jóvenes estudiantes, jóvenes universitarios, y así, lo mismo vale para la palabra pincho y la palabra mozo como se vio más arriba, en parte.

Según lo dicho anteriormente, predomina respecto de la palabra mozo, la actividad y la edad. Luego, vienen las características sexuales y corporales, y el estado civil de la persona. Otro grupo lo integran aquellos nombres asociados a la palabra muchacho, a, a partir de esta nueva red o campo semántico.

Veamos, a continuación, las connotaciones de «muchacho», apodo con el que también nos referimos a joven, pero esta vez, desde una perspectiva social parcialmente distinta, a saber: «Muchacho, cha. (Del ant. mochacho, y este de mocho). 1 . m. y f. Niño que no ha llegado a la adolescencia. 2. m. y f. Niño que 
mama. 3. m. y f. Mozo que sirve de criado. 4. m. y f. coloq. Persona que se halla en la mocedad. U. t. c. adj.».

Muchacho y mozo se asocian, según indica la acepción 3, en la palabra criado. Pero nótese que en las acepciones de mozo no aparece muchacho. Tampoco mozo hace alusión a niño. Entonces, resulta importante para la visión sociopolítica adoptada en este artículo, el contraste semántico que se produce al asociarse la palabra muchacho con el concepto de niño. Por último, cuando la palabra muchacho se conceptualiza desde la edad, se refiere a niño, más que a joven, $\mathrm{y}$, en cambio, cuando se refiere a joven, lo hace desde una valoración social y ética, que lo asocia a mocedad y a mozo, en el sentido de actividad, actitud y conducta. Con la asociación entre muchacho y niño, aparece una alusión a los límites entre una edad y otra, difusa y confusa distinción, que trataremos de aclarar, tomando en consideración los grados de protagonismo histórico, según el estatus social.

El cuarto paso es recurrir a los antecedentes que, históricamente, contextualizan el uso de los vocablos y explican las condiciones sociales e históricas en las que se desenvolvían los sujetos jóvenes:

Para los jóvenes oligarcas, el protagonismo histórico comenzaba cuando cumplían «la edad» del viaje de estudios, o el de su «estreno en sociedad» (para casarse), su ingreso a la política o cuando asumían la gerencia de una empresa familiar. (Salazar, 2002: 48)

Según Salazar (2002), es notorio el contraste entre esta juventud de «arriba» y la juventud de «abajo». Para esta última, el protagonismo histórico comenzaba «poco después del nacimiento» (Salazar, 2002: 48).

Los siguientes vocablos — niño bitongo, zangolotino, de la rollona- dan muestra de otro tipo de ambigüedades, entre niño y muchacho. En el DRAE se dice: «Muchacho que quiere ser o a quien se quiere hacer pasar por niño».

Los jóvenes, llamados mozo, pincho, muchacho, o con otros apodos que veremos a continuación, en su mayoría, se establecen en el campo, en el mundo rural, pero, como se sabe, muchos de ellos, en un constante flujo y desde hace siglos, emigran a la ciudad. En esta, seguramente, seguirán sirviendo, pero no en los mismos oficios o actividades, ni menos con el mismo tipo de jefe o jerarquía.

Esto podría generar un cambio de apodo, en el que, probablemente, se aluda a su forma rural de ser o a su cambio de actividad, como sería el caso, de gatera, chaval, canilla, granuja, changador, y, más recientemente, encuestadore/as, promotore/as, reponedore/as, vendedore/as, repartidores, cargadores, auxiliar de bus, empaquetadores, etc.: 
Un adolescente laborioso venido del campo podía, en ese contexto, iniciar una «carrera transversal» por todos los bajos empleos «de servicio» (no industriales) que ofrecía, por entonces, la gran ciudad, copero, mozo, ascensorista, cochero, chofer. (Salazar 2002: 175)

Los antecedentes históricos nos señalan las causas de esta «diáspora» del campesinado pobre o empobrecido:

Las paulatinas transformaciones en el modo de producción económico político dominantes con posterioridad a la guerra de independencia. El paso de las estructuras coloniales - fundamentalmente agrícolas, ganaderas, comerciales y de pequeña minería - hacia la gestación de estructuras capitalistas sostenida en progresivos procesos de industrialización. (Duarte, 2012: 101)

Estos jóvenes, sujetos históricos, se trasladaron desde el inicio de la República, en el caso chileno, hasta el extremo norte del país y más allá de la cordillera de los Andes, hacia Perú, Argentina y California. En estos países se dedicaron a las labores de extracción minera, y su identidad quedó bajo el nombre de «barretero», «apir», «mapochino» o «chileno».

Sin embargo, un grupo importante de jóvenes no fue capaz de adaptarse a los cambios y prefirieron crear su propio sistema de subsistencia:

Parte importante de los llamados «bandidos» eran jóvenes e inexpertos gañanes (...). Bastaba un buen dato que era socializado entre los pares en chinganas, carreras de caballo, en los suburbios de las ciudades donde se hacían las «invitaciones» a saltear o robar animales. (Palma, 2011: 31)

Al parecer, incluso, varios de los que eligieron continuar como mozo, criado o sirviente, al poco tiempo, caían en la tentación del dinero fácil y rápido:

Un segundo contingente de robo (...) involucró a los sirvientes domésticos y dependientes de tiendas, hoteles u otro tipo de negocios (...). La tónica está marcada por sirvientes de ambos sexos, a menudo, muy jóvenes. (Palma, 2011: 73)

Parece que la situación fue empeorando y se unieron más jóvenes a este tipo de conducta anómica: 
Aunque el robo ha sido históricamente de todas las edades, la mayoría de los ladrones suelen ser jóvenes menores de treinta años. (Palma, 2011: 143)

Se trata, mayoritariamente, de jóvenes que «padecían del abandono familiar y mataban el tiempo en las calles» (Palma, 2011: 144). Según Palma (2011), los chilenos que engrosaban las listas de reos eran sobre todo los llamados «peones-gañanes» (Palma, 2011: 148).

Sin embargo, no todo es trabajo, honesto o deshonesto, también la juventud se identifica con los estudios, con la escuela, el liceo y la universidad, alumnos, pupilos, liceanos, escolares, universitarios, estudiantes, secundarios, penecos, mechones, novatos, cachorros, penecas, matuchos, cadetes, reclutas, pingüinos, encapuchados, tontos útiles, inútiles subversivos, etc., son sobrenombres que ayudan a simbolizar el genio y la figura del joven y la juventud de lápiz y cuaderno, «ilustrada»y, al juzgar por los ejemplos, poco a poco «politizada»y «criminalizada». Al parecer, una especie de «masa crítica alzada».

\section{REPERTORIO DE APODOS}

El repertorio fue sacado de dos diccionarios de americanismos y de un diccionario de chilenismos. Posteriormente, se corroboraron, en cuanto a presencia o ausencia del mismo, con el DRAE, para probar la extensión del uso dentro de la lengua española de América y España.

Las acepciones o connotaciones contextuales que entrega el diccionario por cada palabra nos informan de matices diacrónicos, diatópicos, diastráticos, diafásicos, que se ven como representaciones de tipo social y cultural y, al mismo tiempo, implica que el vocablo es usado en las comunidades que se alude. Por ejemplo, si es chilenismo, peruanismo, si cambió de significado a través del tiempo, si solo es de uso informal, familiar o laboral, etc. Si no aparecen marcas de este tipo, se entiende que no hay usos particulares y, en consecuencia, es de uso generalizado o estándar.

Lo anterior repercute en la cantidad de acepciones de cada palabra y, por lo mismo, en el número de contextos o ámbitos del saber y de la experiencia en los que se usa. Piénsese en las palabras joven, muchacho o mozo, con más de siete acepciones cada una y en las palabras gurí, efebo, gatera, que no alcanzan las dos acepciones cada una. Esto tiene implicancias en la trayectoria del concepto y de la palabra, en la realidad social y cultural de las comunidades, grandes o pequeñas, dominantes o dominadas, mayores o menores, superiores o inferiores. 


\subsection{ClasificaCión GeneraL}

La agrupación de este tipo de vocablos se realizó considerando las connotaciones más relevantes de su asociación semántica indicada en cada acepción referida a las palabras joven y juventud. En el fondo, son los sentidos que puedan dar cuenta de los valores sociopolíticos, a saber: 1) sociorracial, 2) edad, 3) psicosocial, 4) estado civil, 5) actividad, labor, oficio, 6) apariencia física. Cada casillero representa una visión o una cualidad enfatizada por el vocablo analizado. En su conjunto, revelan la identidad social, histórica y política del concepto de joven y juventud.

Por razones de espacio, este artículo indicará solo los apodos y no sus acepciones, sin embargo, dichas expresiones se presentan clasificadas como forma de explicitar el concepto de joven y juventud dentro del valor sociopolítico descrito.

\section{Sociorracial}

Con este tipo de apodo nos referimos al origen racial del joven. Se consideran el color de la piel, el tipo de cara, la altura, etc. El énfasis está en los aspectos raciales del cual se desprende un sentido de jerarquía social. Así, entre más blanco, mejor posición tendría en la escala social, en cambio, si el color tiende a oscurecerse, entonces su posición sería la más baja de las categorías sociales.

Gurí; gueñi; longo; canela.

\section{Edad}

En este aspecto, las acepciones se refieren al sujeto joven, relacionándolo con la edad. Esta se vincula con los pocos años de vida y con las conductas que personas de poca edad, y tiende a ser despectivo, pues se asocia la poca edad con la falta de experiencia.

bato; chamaco ,a; chico; garbancero; gurrumino, na; quinceañero; mozalbete; mozuelo, la; pelón; pibe, pibito; niño, ña; pollo; tajalón; patojo, ja; volantón.

\section{Psicosocial}

En esta categoría, reuní a aquellos apodos que nombran al joven según alguna conducta, actitud o comportamiento social. En general, se perciben conductas reprobables o negativas.

Cachaco, ca; catrín; colérico; chaval; chavo, va; chorcha; damisela; efebo; galopin

Gatera; granuja; guaina; HIPPIE O HIPPY; loco, ca; mancebo, ba; malinche; marocha; niño bien; niño bitongo, ga; niño gótico, ca; niño zangolotino, na; 
pachuco, ca; palomilla; señorito, ta; patiquín; patota; pinche; pimpollo; zanahoria; pirujo, ja.

\section{Estado civil}

Los apodos de esta categoría son indicadores de un vínculo entre el concepto de joven y las relaciones maritales, extramaritales y de noviazgo. Este tipo de relación con el concepto de joven también está asociado al celibato y a la virginidad.

Creo pertinente aportar con la siguiente nota para entender algunos antecedentes que aluden a la asociación, casamiento, familia y juventud: «Si los hombres que eran peones "no formaban familia", era porque un "peón-gañán" no podía, ni él mismo, mantenerse con el jornal que pagaban entonces por su trabajo» (Salazar, 1990, citado en: González, 2011: 229). Por otro lado, esta condición de soltería convenía a los patrones que contrataban a los peones, llamados estables, debido a que el hombre soltero «tenía mayor flexibilidad para atender a los requerimientos del patrón» (González, 2011: 229).

Por lo mismo, pese a las escasas dos palabras en esta sección, se puede inferir que, de acuerdo con las citas transcritas, los jóvenes trabajadores del campo, mozos, peones, gurí, serían célibes. Sin embargo, es una acepción no oficializada en los diccionarios consultados y es posible entender que esta acepción está implícita en las palabras referidas a la realidad de joven y juventud.

Doncel; doncella.

\section{Actividad}

La categoría que presento tiene apodos, cuyos sentidos refieren a los trabajos, oficios, labores, quehaceres. Quizá este tipo de palabras es la que más indica alguna asociación con lo que buscamos. El rol laboral del joven es una variable sociopolítica que marca una visión muy distinta frente al joven, toda vez que es uno de los hitos fundamentales para el ingreso de este al mundo adulto.

Arrenquín; espolique; cadete; canilla; cajonero; chumero; galopín; galopillo; gañán; júnior; zagal, la; mochil; motil; motril.

\section{Apariencia física}

El grupo de apodos pertenecientes a esta categoría dan cuenta de la visión del cuerpo joven y las formas de vestirlo. A su vez, esta forma de vestir se relaciona con conductas que resaltan el cuidado y la delicadeza en el vestir. Este tipo de apodo connota ironía y a veces burla, debido a la incongruencia entre las vestimentas y la identidad con la clase social. 
Chigüín, na; chute; grandullón; imberbe; lechuguino; macuco, ca; mocetón, na.

\section{CONCLuSiOneS}

Surge la idea de, a lo menos, dos tipos de jóvenes y, al mismo tiempo, damos cuenta de una relación social entre personas, en los que:

Los elementos connotativos del apodo, enfatizan una serie de condicionamientos sociales. Entre más bajo el nivel social, mayor carga del sobrenombre soportará. (...). Y, muchas veces, éste es verdaderamente altisonante. (McDonald, 2009)

Un ejemplo ilustrativo de este tipo de relación social, representado en los recursos expresivos indicados, es el que se usa en la siguiente cita:

No hay sólo «una» juventud (la del divino tesoro) sino varias. Que la «masa juvenil» no es socialmente homogénea, sino diversa. (...). De modo que, cuando menos-para no hilar demasiado fino- cabe distinguir una jeunesse doreé («caballeritos») y una jeunesse de la galére («cabros de la calle», «huachos», «pelusas»). (Salazar, 2002: 11)

Es evidente que la clase es un factor importante para valorar socialmente lo joven y lo juvenil, a través de la elección de uno u otro apodo. Este clasismo tiene, además, mucho de racismo y sexismo, los que, en su conjunto, determinan otros asuntos relacionados con cada una de las juventudes de las que se tenga en cuenta; estas pueden ser, la juventud estudiantil, trabajadora, política, religiosa, anarquista, urbana, rural, blanca, mestiza, negra, hispanoamericana, chilena, hispana, femenina, masculina, deportista, sedentaria, religiosa, atea.

Este tipo de investigación lingüística aplicada al apodo permite descubrir las relaciones sociales que existen entre los distintos grupos, dentro de una misma comunidad. Los apodos son representativos de una relación sociopolítica que surge en determinados momentos de tensión histórica y que dejan huella o forman parte de la memoria colectiva.

El apodo es un recurso expresivo que sirve a los grupos de mayor poder económico y político para nominar, con el propósito de dominar social y políticamente a los estratos más bajos o pobres de la comunidad nacional o internacional. 
Este fenómeno forma parte de un proceso de resemantización, en el que ciertos nombres van cambiando de sentidos producto de tergiversaciones, descontextualizaciones y manipulaciones del mismo, para establecer asociaciones convenientes y adecuadas a los fines de quienes gobiernan, es decir, hacer que los gobernados no solo parezcan diferentes, sino también por eso, inferiores.

En el caso del apodo sociopolítico referido al grupo etario de los jóvenes, tenemos dos tipos de casos, los referidos a la juventud de clase alta y a la juventud de clase baja. A su vez, los apodos son clasificados según valores sociopolíticos que dan cuenta de los sentidos y connotaciones sociales que tienen dentro de un contexto histórico común, los que en su mayoría son más bien negativos que positivos. En este caso, el apodo para jóvenes dice relación con aspectos raciales, conductuales, físicos, formas del vestir y psicológicos, en un contexto social en el que domina la visión del adulto gobernante.

En este sentido, hay que distinguir cómo es la juventud y cómo la vemos, la visualizamos, la caricaturizamos, la representamos, la identificamos, la imaginamos, lingüísticamente, pero que en el fondo representa cómo la sociedad no juvenil, especialmente la adulta dirigente, gobernante, es decir, dominante, percibe, define y construye un imaginario de juventud y joven. Aquí solo veremos el inicio de un largo camino.

RECIBIDO: 26 DE ABRIL DE 2018

ACEPTADO: 25 DE MARZO DE 2019 


\section{BIBLIOGRAFÍA}

CAMPA, R. (1998). El trayecto de las palabras. La antigüedad itálica y las lenguas neorromances de la Europa contemporánea. Buenos Aires: Eudeba.

DicCiOnaRio De AMERICANISMOS. (1983). Diccionario ilustrado Sopena. Barcelona: Ramón Sopena.

Diccionario de la Real Academia de la Lengua Española. (2001). 22ª edición. Disponible en:

http://buscon.rae.es/drae/?type=3\&val=quina\&val_aux=\&origen=REDR $\mathrm{AE}$

DUARTE QUAPPER, C. (2012). «Sociedades adultocéntricas: sobre sus orígenes y reproducción». Última Década, 36: 99-125.

GamboA, A. y PincheIRA, I. (2009). Organizaciones juveniles en Santiago de Chile. Invisibles_subterráneas. Santiago: Lom Ediciones.

GAUNE, R. y Lara, M. (2010). Historias de racismos y discriminación en Chile. Santiago: Uqbar.

GonZÁlez Le SAUX, M. (2011). De empresarios a empleados: clase media y estado docente en Chile 1810-1920. Santiago: Lom Ediciones.

KANY, CH. (1962). Semántica hispanoamericana. Madrid: Aguilar.

Magendzo K., A. y Donoso F. P. (2000). Cuando a uno lo molestan. Un acercamiento a la discriminación en la escuela. Santiago: Lom Ediciones.

Malaret, A. (1946). Diccionario de americanismos. Buenos Aires: Emecé.

MCDonALD, R. (2009). «Los apodos chapines literatura, retórica, semiótica: el apodo como significación de las características físicas del cuerpo». Ponencia del Departamento de Ciencias de la Comunicación en VIII Congreso Internacional de Filosofía de las Concepciones Contemporáneas de la Corporeidad, 11-13 de agosto, Facultad de Humanidades, Universidad Rafael Landívar, Guatemala. Disponible en: http://diariodelgallo.files.wordpress.com/2012/03/los-apodos-chapinessemiotica-delapodo-en-guatemala.pdf

Palma Alvarado, D. (2011). Ladrones: Historia social y cultural del robo en Chile, 1870-1920. Santiago: Lom Ediciones.

Soura SAlvo, C. (1937). «Tipos chilenos en la novela y en el cuento nacional». Prensas de la Universidad de Chile. Disponible en: http://www.revistas.uchile.cl/index.php/ANUC/article/viewPDFInterstiti $\mathrm{al} / 24776 / 26144$ 
TORRES DUJISIN, I. (2010). El imaginario de las elites y los sectores populares. 1919-1922. Santiago: Universitaria.

RodRíGUEZ, Z. (1977). Diccionario de chilenismos (edición facsimilar a la de 1875). Valparaíso: Ediciones Universitarias de Valparaíso. Revista Signos, X, 1(14). 